\title{
Forum
}

PMLA invites members of the association to submit letters, printed and doublespaced, that comment on articles in previous issues or on matters of general scholarly or critical interest. The editor reserves the right to reject or edit Forum contributions and offers the PMLA authors discussed in published letters an opportunity to reply. Submissions of more than one thousand words are not considered. The journal omits titles before persons' names and discourages endnotes and works-cited lists in the Forum. Letters should be addressed to PMLA Forum, Modern Language Association, 26 Broadway, 3rd floor, New York, NY 10004-1789.

\section{Defining Allusion}

\section{To THE EDITOR:}

Gregory Machacek’s “Allusion” (122 [2007]: 522-36) deals with the vagueness of the word in its title and others in the neighborhood by choosing both horns of the lexicographer's dilemma. Critical terminology exemplifies what I. A. Richards called "the chaos of critical theories" and W. B. Gallie more temperately characterized as "essentially contested concepts." To clarify and organize the terms, one must stipulate how they will be defined. The alternative-to describe how critics and scholars use the words-can appear to be a dutiful enumeration of confusions.

Machacek yields to both impulses, stipulation and description. He lays out how we should use allusion but simply describes the nineteenthand twentieth-century meanings of world without challenging either. Instead of accepting the difference between continental and American ideas of intertextuality and yielding to usage, he insists on the broadest possible meaning for the word, "all possible forms of textual interrelation," which would subsume motifs, topoi, myths, themes, plots, genres, verse forms, period styles, and modes (tragedy, romance, satire, and the like [525]). Once again, prescription trumps usage, in the interests of "terminological rigor" (522).

The attempt to provide a rigorous definition of allusion is beset by difficulties. Machacek first defines it as "distinguishable primarily by being brief, discrete, and local and evoking a single text that the culture of the alluding writer associates with an identifiable earlier author" (525). The next page yields another definition: the word refers to "a poet's incorporation into a poem of a short phrase reminiscent of a phrase in an earlier work of literature." The first definition says allusion can occur anywhere in literature; the second allows for allusion only in poetry. The first specifies that the allusion must be to an identifiable author, whereas the second

(C) 2008 BY THE MODERN LANGUAGE ASSOCIATION OF AMERICA 
admits works whose author may be contested, multiple, or unknown (the epics of "Homer," ballads, and biblical books, for example).

I honestly don't know what Machacek means by "literature." Philologists and new historicists would have it include tracts, travel books, edicts, and speeches. Machacek distinguishes "[a]llusions to earlier authors" from "the relations between literary texts and ... accounts of the colonial enterprise, medical treatises, and the whole host of other contemporaneous texts" (531). It seems that the latter are not literature, despite the fact that they have authors and that phrases from them appear in plays. Machacek also refers to the distinction between "earlier" and "contemporaneous" texts as one between diachronic and synchronic relations. The example he provides of "diachronic intertextuality" puzzles me (531). He cites Christopher Marlowe's "Nymph's Reply to the Shepherd" as a poem written to "answer an earlier literary work" (525). That earlier work was written by Sir Walter Raleigh, in reply to Marlowe's "The Passionate Shepherd to His Love." The point is not the confusion about authorship but the fact that the complete versions of both poems first appeared in the same volume, England's Helicon (1600). All references to other texts are of course diachronic, but this example of diachrony in 1600 collapses the distinction between diachrony and synchrony, or earlier and contemporaneous texts.

In concluding his article, Machacek refers to "the species of allusion that I have referred to as phraseological adaptation," apparently granting that the genus has other species (535). That is a prudent concession, given the fate of all attempts to specify what such terms should mean. Udo J. Hebel's Intertextuality, Allusion, and Quotation: An International Bibliography of Critical Studies (New York: Greenwood, 1989) lists over two thousand works on the subject, and there have been many more in the past nineteen years.

Greek and Roman critics escaped one of our terminological problems because they didn't have a word for allusion; nevertheless, they were able to provide us with examples of the phenomenon. Their most common words for connections between authors were aemulatio (emulation or rivalry; jealousy, envy) and philoneikia (love of strife, rivalry, contentiousness). Machacek and many poststructuralists highlight terminological issues, whereas classical and current critics emphasize contexts-the referential dimension in which people, motives, and historical circumstance play havoc with the notion that if we get the words right, we will have a dependable way to discuss literary realities. The latter part of Machacek's article introduces such issues into the discussion and can be read with profit even if we are not attending to his strictures about what literary terms should mean. Paul de Man might have characterized this turn in the article as an instance of blindness producing insight. Such changes provide evidence that, just as we can't stipulate what writers should mean by world (which even Wordsworth used in different senses), so literary critics cannot separate their textual terminology from the writers and worlds that texts embody.

Wallace Martin

University of Toledo

\section{Reply:}

This too is text, nor am I out of it.

Wallace Martin rightly characterizes the dilemma that faces would-be lexicographers as they use words to draw boundaries between words, and he tents me to the quick where my definitions do not entirely square with one another or where they defer to other words, themselves inadequately defined. I appreciate his comments. This strife is good for mortals.

Though I thought of my essay as proposing potentially useful definitions rather than "stipulating" them, I nevertheless welcome the opportunity to clarify: I do not regard allusion as existing only in poetry (as opposed to "anywhere in literature") or as pointing only to identifiable authors. But if I were to offer a revised definition - the incorporation into one work of a short phrase reminiscent of a phrase in an earlier work of literature-we might still find the definition inadequate, even assuming the broader meaning 